\author{
Maria Antonietta Palmas \\ Alessandra Cherchi \\ Erminia Stochino \\ Donatella Congiu \\ Maria Del Zompo
}

\section{Dopamine genes and migraine}

M.A. Palmas • A. Cherchi

E. Stochino $\bullet$ D. Congiu

M. Del Zompo (凶)

Headache Center, Department of

Neurosciences B.B. Brodie,

University of Cagliari,

Via Porcell 4, I-09124 Cagliari, Italy

e-mail: delzompo@unica.it

Tel.: +39-070-6092438

Fax: +39 070-653584

\begin{abstract}
Migraine is a common chronic disorder with an etiology still mostly unknown. Several neurotransmitters such as dopamine and serotonin are considered to be involved in the pathogenesis of the disease and the study of their systems is crucial in the understanding of migraine. Dopaminergic receptors are variously represented in human CNS and periphery. The hypothesis that a hypersensitivity of the dopaminergic system may have a
\end{abstract}

role in migraine is based on clinical and genetic data. Genetic data are represented by association studies using dopaminergic genes as candidate genes which show that the D2 receptor gene appears to be involved in the pathogenesis of migraine.

Key words Migraine • Genetics • Dopamine $\cdot$ Hypersensitivity

\section{Introduction}

The study of the pathophysiological mechanisms of migraine includes the investigation of the neurotransmitter systems and their potential role in the development of the attack. Since the 1970s, many authors have studied the involvement of the dopaminergic system in the pathogenesis of the disease. Based on their structure and pharmacological characteristics, dopamine receptors have been classified into two main families: D1, including D1 and D5, and D2, including D2, D3 and D4. The dopaminergic system has a prominent role in motor and sensorial control, in the modulation of cognitive processes, and in the control of both prolactin and growth hormone secretion. Recently, a key role in the regulation of cerebral microcirculation has been demonstrated [1].

The theory that hypersensitivity of the dopaminergic system is involved in the pathogenesis of migraine has been supported by various authors on the basis of clinical, pharmacological and recent genetic evidence. Clinical evidence of dopamine involvement was first described by Blau, who observed intense yawning, craving for some foods and altered sensorial perception during the initial phase of a migraine attack [2]. Yawning is a behavior controlled by numerous neurotransmitters and by neuropeptides which act at the level of the periventricular hypothalamic nucleus. Among the various neurotransmitters which elicit yawning, dopamine has proved to play a major role, acting through D2 postsynaptic receptors located in cell bodies of oxytocinergic neurons present in the periventricular hypothalamic nucleus, causing the release of oxytocin and subsequent yawning [3]. During attacks, nausea and/or vomiting, dysosmia and more yawning may occur. Nausea and vomiting are partly controlled by the activation of dopaminergic system through $\mathrm{D}_{2}$ receptors located in the "chemoreceptor trigger zone" (CTZ) and in the nucleus of solitary tract in the brainstem. Dysosmia indicates an activation of the olfactory tubercle, which is particularly rich in dopaminergic fibers. Other clinical aspects of migraine, such as gastrointestinal disorders, may also be ascribed to a dysfunction of the dopaminergic system. The administration of a very low dose of apomorphine, a selective $D_{1}$ and $D_{2}$ dopaminergic agonist, to a migraineur caused an episode of nausea, sweating, yawning, hypotension, vomiting and syncope, which further suggests the existence of a hypersensitivity of the dopaminergic system in migraineurs [4]. 
However, the cause of this dopaminergic hypersensitivity is not clear yet: it might be due to a decrease of the neurotransmitter or of a neuromodulator or to an altered function of dopaminergic receptors. Further clarification is required as to whether dopaminergic hypersensitivity is due to an increased number or sensitivity of dopaminergic receptors. Genetic studies may contribute to improve our knowledge in this field.

The prevalence of this disorder among members of the same family suggests the presence of a genetic component for migraine. Of the numerous studies performed to date, none have led to the identification of a specific gene responsible for the disease or its mode of transmission. Only for familial hemiplegic migraine, a rare and peculiar type of migraine, two responsible genes were identified, one located on chromosome 19 and the other on the long arm of chromosome 1 with an autosomal, dominant, high penetrance transmission [5].

We, as other authors, consider migraine to be a "complex disease" which is caused by a combination of various environmental and genetic factors in a similar way to epilepsy, diabetes, hypotension and many other common diseases.

In recent years, various studies have been carried out to verify a possible involvement of dopaminergic system in migraine pathogenesis. A study performed on a sample of 250 patients affected by migraine with aura considered the gene coding for D2 receptor as a candidate gene [6]. As an alternative to case-control studies, the use of trios has been proposed. A trio is constituted by an affected proband and his/her parents, whereas the control group is represented by non-transmitted alleles of parents. An allele of a genetic marker is associated with the disease if it shows a significantly higher frequency in the affected group than control. This method is preferred when geographic or ethnic stratifications may provide false results. A study with these characteristics was performed by our group in a randomized sample of 50 trios, each trio consisting of a subject affected by migraine without aura and his/her parents. In this study, we analyzed the genes coding for D1, D2, D3 and D4 receptors as candidate genes. Data obtained from the first group of 50 triads showed a positive association between the "dopaminergic" phenotype of migraine without aura and the D2 receptor gene [7]. To add new data, we studied the D5 receptor gene in a sample of 100 trios.

\section{Materials and methods}

\section{Subjects}

We selected 100 trios constituted by a proband and both parents with a Sardinian descent of at least four generations among the patients followed at our Headache Center, Department of Neurosciences, University of Cagliari. Probands were diagnosed with migraine without aura according to IHS criteria [8]. Patients were enrolled in the study independently upon their familiar history. All probands and their parents were directly interviewed by two physicians at the Headache Center, and a blood sample (10 ml) was drawn. All participants in the study gave their informed consent prior to their enrollment in the study. Regarding the symptoms of migraine attacks, the presence of symptoms caused by altered function of the dopaminergic system, such as nausea and yawning, allowed us to identify a subgroup of 49 dopaminergic probands.

\section{Genotyping}

High molecular weight DNA was isolated from venous blood according to routine procedures. A polymorphic microsatellite (CT)6 (GT)21 (GA)13 was identified according to Sherrington et al. [9]. Polymerase chain reaction (PCR) amplification was performed in a $25 \mu \mathrm{l}$ reaction containing $100 \mathrm{ng}$ genomic DNA, $1.5 \mathrm{mM} \mathrm{MgCl}_{2}$, $50 \mathrm{mM} \mathrm{KCl}, 10 \mathrm{mM}$ Tris $\mathrm{HCl}$ (pH 8.3), $200 \mu \mathrm{M}$ dNTP, 1 unit Taq polymerase and 25 pmol of each primer (primer 1, CGTGTATGATCCCTGCAG; primer 2 GCTCATGAGAAGAATGGAGTG). Primer 2 was labeled with ${ }^{32} \mathrm{P}$ using T4 polynucleotide kinase. The cycling conditions for the DRD5 microsatellite were $94^{\circ} \mathrm{C}$ for 5 min, followed by 30 cycles of $58^{\circ} \mathrm{C}, 72^{\circ} \mathrm{C}$ and $94^{\circ} \mathrm{C}$, each for 30 $\mathrm{s}$. The final extension step was performed at $72^{\circ} \mathrm{C}$ for $10 \mathrm{~min}$. PCR products were resolved on $5 \%$ denaturating polyacrilamide gel and autoradiographed for $12 \mathrm{~h}$. Genotypes were scored independently by two investigators blind to clinical diagnosis.

\section{Statistical analysis}

Statistical analysis was performed using the transmission disequilibrium test (TDT), a "family-based" test proposed by Spielman [10]. TDT is based on the detection of disproportionate transmission of alleles by heterozygous parents to affected children. The mendelian expectation under the null hypothesis of no association is that either allele carried by a heterozygote has a 50:50 chance of transmission to an affected child. If the allele plays a role in the disorder, then its transmission should exceed $50 \%$.

Data were analyzed using the computer program ETDT (version 1.8) [11]. This package performs the TDT test for a marker with multiple alleles. In addition, we used MCETDT that performs Monte Carlo simulation as described by Sham and Curtis [12].

\section{Results}

Demographic and clinical data of the 100 probands included in the study are summarized in Table 1. The allele frequencies in probands were similar to the distribution found in other Caucasian populations. TDT did not reveal the presence of a significant association between the D5 receptor gene and migraine without aura in the total sample of 100 trios (Table 2). The subgroup of probands with dopaminergic symptoms (49 of 100 trios) also gave negative results (Table 3). Monte Carlo simulations provided similar negative results (data not shown). 
Table 1 Characteristics of 100 Sardinian probands with migraine without aura

\begin{tabular}{lccc}
\hline Variable & $\begin{array}{c}\text { Total } \\
(\mathrm{n}=100)\end{array}$ & $\begin{array}{c}\text { Dopaminergic } \\
(\mathrm{n}=49)\end{array}$ & $\begin{array}{c}\text { Other } \\
(\mathrm{n}=51)\end{array}$ \\
\hline Males, $\mathrm{n}$ & 14 & 10 & 4 \\
Mean age, years (range) & $30 \pm 8(17-55)$ & $30.3 \pm 7.2(18-46)$ & $30.6 \pm 9.6(17-55)$ \\
Mean age at onset, years (range) & $15.0 \pm 7.0(5-40)$ & $14.4 \pm 6.2(5-30)$ & $15.1 \pm 8.0 \quad(5-40)$ \\
Symptoms, no. of patients & & 49 & 33 \\
Nausea & 82 & 49 & 9 \\
Yawning & 58 & 49 & 0 \\
Nausea and yawning & 49 & 43 & 39 \\
Phonophobia & 82 & 40 & 39 \\
Photophobia & 79 & & \\
\hline
\end{tabular}

Table 2 Association between migraine without aura and D5 gene in a Sardinian sample (100 trios) ${ }^{\mathrm{a}}$

\begin{tabular}{lllllllllllll}
\hline Allele & 1 & 2 & 3 & 4 & 5 & 6 & 7 & 8 & 9 & 10 & 11 & 12 \\
\hline Transmitted & 3 & 4 & 20 & 28 & 43 & 15 & 1 & 6 & 7 & 7 & 7 & 5 \\
Not transmitted & 4 & 4 & 21 & 24 & 43 & 12 & 5 & 2 & 7 & 10 & 7 & 7 \\
\hline
\end{tabular}

${ }^{\mathrm{a}}$ Chi-squared for allele-wise $\mathrm{TDT}=7.02, \mathrm{df}=11, p=0.79$

Table 3 Association between migraine without aura and D5 gene in a Sardinian sample of 49 trios with dopaminergic symptoms ${ }^{\mathrm{a}}$

\begin{tabular}{lllllllllllll}
\hline Allele & 1 & 2 & 3 & 4 & 5 & 6 & 7 & 8 & 9 & 10 & 11 & 12 \\
\hline Transmitted & 2 & 3 & 10 & 15 & 22 & 8 & 0 & 2 & 3 & 3 & 3 & 3 \\
Not transmitted & 1 & 3 & 11 & 14 & 22 & 5 & 1 & 2 & 4 & 2 & 6 & 3 \\
\hline
\end{tabular}

${ }^{\text {a }}$ Chi-squared for allele-wise TDT $=4.33, \mathrm{df}=11, p=0.96$

\section{Discussion}

Our data confirm that, other than the gene coding for D2 receptor, no other dopaminergic genes are involved in migraine. Particularly, the D5 dopaminergic receptor does not seem to be involved in the pathogenesis of migraine.

However, the importance of dopamine in the etiopathogenesis of migraine is still supported by numerous data and evidence. Assembling clinical and pharmacological data with new genetic hypotheses is not easy, but some speculations may be drawn. Migraine is characterized by a low threshold of neuronal excitability regulated by genetic factors which could involve the dopaminergic system. Modifications in the dopaminergic system, also on a genetic basis, could be reflected at the level of local cerebral microcirculation, starting or amplifying all those mechanisms leading to the release of neuropeptides and other mediators of pain which are involved in migraine process. The fact that an acute attack can be successfully treated with dopamine antagonists and that preventive therapies with low doses of dopamine agonists are effective in desensitizing the dopaminergic system, together with recent genetic data, may give a valid contribution for new therapeutic strategies. We will study the genes encoding some proteins involved in the signal transduction of the D2 receptor, as candidate genes in our 100 trios sample.

Acknowledgement This study was partly financially supported by Italian "Ministero Università e Ricerca Scientifica e Tecnologica" (MURST). 


\section{References}

1. Krimer SK, Muly III EC, Williams GV, Goldman-Rakic PS (1998) Dopaminergic regulation of cerebral cortical microcirculation. Nat Neurosci 1:263-265

2. Blau JN (1992) Migraine: theories of pathogenesis. Lancet 339:1202-1206

3. Argiolas A, Melis MR (1998) The neuropharmacology of yawning. Eur $\mathbf{J}$ Pharmacol 343:1-16

4. Del Zompo M, Lai M, Loi V, Pisano MR (1995) Dopamine hypersensitivity in migraine: role in apomorphine syncope. Headache 32:222-224

5. Gardner K, Hoffman EP (1998)

Current status of genetic discoveries in migraine: familial hemiplegic migraine and beyond. Curr Opin Neurol

11:211-216
6. Peroutka SJ, Wilhoit T, Jones K (1997) Clinical susceptibility to migraine with aura is modified by dopamine D2 receptor (DRD2) NcoI alleles. Neurology 49:201-206

7. Del Zompo M, Cherchi A, Palmas MA, Ponti M, Bocchetta A, Gessa GL, Piccardi MP (1998) Association between dopamine receptor genes and migraine without aura in a Sardinian sample. Neurology 51:781-786

8. Headache Classification Committee of the International Headache Society (1998) Classification and diagnostic criteria for headache disorders, cranial neuralgias and facial pain. Cephalalgia 8[Suppl 7]:1-96
9. Sherrington R, Mankoo B, Attwood J, Kalsi G, Curtis D, Buetow K, Povey S, Gurling H (1993) Cloning of the human dopamine D5 receptor gene and identification of a highly polymorphic microsatellite for the DRD5 locus that shows tight linkage to the chromosome $4 \mathrm{p}$ reference marker RAF1P1.

Genomics 18:423-425

10. Spielman RS, McGinnis RE, Ewens WJ (1993) Transmission test for linkage disequilibrium: the insulin gene region and insulin-dependent diabetes mellitus (IDDM). Am J Hum Genet 52:506-516

11. Sham PC, Curtis D (1995) An extended transmission disequilibrium test (TDT) for multi-allele marker loci. Ann Hum Genet 59:232-336

12. Sham PC, Curtis D (1995) Monte Carlo tests for associations between disease and alleles at highly polymorphic loci. Ann Hum Genet 59:97-105 